\title{
Relationship between sRAGE and hsCRP as Markers of Cardiovascular Disease Risk Factors in Diabetic and Non-Diabetic Men with Central Obesity
}

\author{
Rambu Beppy Hamuaty ${ }^{1}$, Indriyanti Rafi Sukmawati ${ }^{1}$, Ferry Sandra ${ }^{2,3}$ \\ ${ }^{1}$ Prodia Clinical Laboratory, Solo, Indonesia \\ ${ }^{2}$ Department of Biochemistry and Molecular Biology, Division of Oral Biology, Faculty of Dentistry, Trisakti University, Jakarta, \\ Indonesia \\ ${ }^{3}$ Doctoral Program in Medical Science, Faculty of Medicine, University of Sumatera Utara, Medan, Indonesia
}

Background: Interaction between advanced glycation end product (AGE) and receptor for AGE (RAGE) triggers the escalation of inflammatory cytokine expressions. High-sensitivity C-reactive protein (hsCRP), an important inflammatory marker, has been reported to be modulated by soluble RAGE (sRAGE). However, the relationship between hsCRP and sRAGE in diabetes was not clearly described. Therefore present study was conducted to determine the relationship between sRAGE with hsCRP in men with central obese diabetic and non-diabetic.

Materials and Methods: Adult men aged 25-60 years with central obese diabetes and non-diabetes, were recruited. Patient's profiles were collected before the physical and blood examination. Physical examinations were conducted by measuring waist/abdomen, blood pressure, height, and weight. The routine blood test was performed to obtain concentrations of fasting blood glucose, HbA1c, hsCRP and sRAGE level.

Results: Fifty-seven subjects with central obese and waist size $\geq 90 \mathrm{~cm}$ were selected. It was found that hsCRP values were significantly different $(p=0.000)$ in $\mathrm{HbA} 1 c<6.5 \%$ dan $\mathrm{HbA} 1 \mathrm{c} \geq 6.5 \%$ groups. There was an inverse relationship between hsCRP and sRAGE levels for both in HbA1c <6.5\% ( $r=-0.073$ ) and HbA1c $\geq 6.5 \%$ ( $r=-0.022$ ) groups. In HbA1c $\geq 6.5 \%$ group, sRAGE showed strong positive correlation with $1 \mathrm{mg} / \mathrm{dL} \leq \mathrm{hsCRP}<3 \mathrm{mg} / \mathrm{dL}$ group $(r>0.5)$.

Conclusion: In the early stages of diabetes with hsCRP $<1 \mathrm{mg} / \mathrm{dL}$, the protective function was demonstrated with greater sRAGE levels. However, in further phase with $3 \leq \mathrm{hsCRP}<10 \mathrm{mg} / \mathrm{dL}$, the level of sRAGE was low, which is assumed to be associated with complications. Hence, sRAGE could be suggested as a complementary marker for hsCRP to evaluate diabetic men with central obesity.

Keywords: sRAGE, hsCRP, diabetes, HbA1c, central obesity

\section{Introduction}

The prevalence of obesity in adult Indonesians increased rapidly from 1993 to 2007, by around 11\% points (from
20.8 to $31.2 \%$ ) in men and $16 \%$ (from 32.0 to $48.8 \%$ ) in women. In contrast, the prevalence of obesity globally rose by about $8.1 \%$ in men and $8.2 \%$ in women from 1980 to 2013. ${ }^{1}$ Thus, the prevalence of obesity in Indonesian women

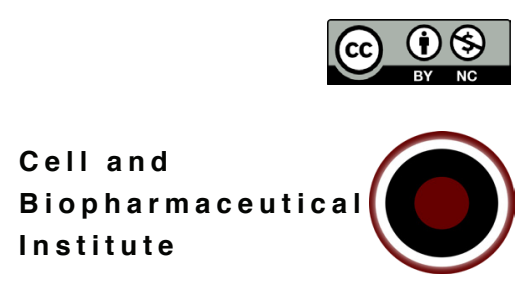

Corresponding Author:

Ferry Sandra

Department of Biochemistry and Molecular Biology, Division of Oral Biology

Faculty of Dentistry, Trisakti University, Jl. Kyai Tapa No.260

Jakarta, Indonesia

E-mail: ferrysandra@gmail.com

Cell and

Institute 
nearly doubled compared with that of women globally. The occurrence of obesity is proposed caused by both physical inactivity and consumption of food. In fact, the increase in obesity has occurred among all socioeconomic groups and cannot be explained genetically.

Accumulation of fat in obese individuals, particularly in visceral obesity is associated with many chronic metabolic disorders characterized by abnormal cytokine production, increased acute phase reactants, mediators, and activation of inflammatory signaling pathways. ${ }^{2}$ Some recent data show the plasma concentration of inflammatory mediators, such as tumor necrosis factor- $\alpha$ (TNF- $\alpha$ ) and interleukin-6 (IL-6) increases in insulin resistance that underlies obesity and type 2 diabetes, which then raises the question of the underlying mechanisms in both conditions. ${ }^{3}$ In addition, plasma level of high-sensitivity C-reactive protein (hsCRP), a marker of inflammation, has been reported as a simple predictor of metabolic syndrome.

Under conditions of hyperglycemia in diabetes, endogenous non-enzymatic glycosylation on proteins and lipids triggers the formation of a heterogeneous product, called advanced glycation end-product (AGE). The bond between AGE and cell surface receptor for AGE (RAGE) produces conduction process of cellular signals that activate nuclear factor (NF)- $\mathrm{kB}$, increase the expression of cytokines and adhesion molecules, and induce oxidative stress. AGERAGE system plays an important role in the development of microvascular complications of diabetes. ${ }^{4}$ Various evidences collected also show that RAGE is involved in macrovascular diabetic complications. ${ }^{5}$

The expression of RAGE is observed in adipocytes as well as immune cells, endothelial cells, and pancreatic $\beta$ cells under certain conditions. It has been reported that RAGE is implicated in adipocyte hypertrophy and insulin resistance. RAGE-mediated regulation of adiposity and inflammation may attribute to type 2 diabetes and diabetic vascular complications. ${ }^{6}$ RAGE provides a new target for the treatment interventions to reduce and prevent the development of side effects of hyperglycemia. It is possible to make personalized therapy against RAGE to inhibit disease progression. ${ }^{7}$

Secreted RAGE isoform, called soluble RAGE (sRAGE), has the ability to prevent the side effects of RAGE signal conduction to act as bait. sRAGE has been successfully used in some animal models which suffered vascular damage mediated by RAGE. ${ }^{8}$ Therefore, the present study was conducted to determine the relationship between sRAGE with hsCRP in men with central obese diabetic and non-diabetic.

\section{Materials and methods}

\section{Subject recruitment and sample collection}

Adult men aged 25-60 years with central obese diabetes and non-diabetes according to body mass index (BMI) of Asia Pacific in 2000 and hemoglobin A1C (HbA1C) results, were recruited in Prodia Clinical Laboratory in Solo, Indonesia. Diabetes Mellitus Consensus 2015 was used as the reference.

\section{Examination and data collection}

Patient's profiles were collected before the physical and blood examination. Physical examinations were conducted by measuring waist, blood pressure, height, and weight. The routine blood test was performed in Prodia Clinical Laboratory, Jakarta and Prodia Clinical Laboratory, Solo, to obtain concentrations of fasting blood glucose, $\mathrm{HbAlc}$, hsCRP and sRAGE level.

\section{Data analysis}

The data obtained were processed by SPSS for Windows version 16 with univariate and bivariate analysis. The significance level was set at $5 \%$.

\section{Results}

\section{General characteristics}

Fifty-seven subjects with central obese and waist size $\geq 90$ $\mathrm{cm}$ were selected. The results of the physical examination showed the average age of the participants was $40.77 \pm 11.31$ years. The subjects were grouped based on $\mathrm{HbAlc}$ and hsCRP (Table 1).

Data from 57 subjects showed that average of $\mathrm{HbAlc}$ was $6.1 \%$, the average of hsCRP was $2.27 \mathrm{mg} / \mathrm{dL}$, and the average of sRAGE was $889.57 \mathrm{pg} / \mathrm{mL}$. The average of

Table 1. General characteristics of subjects.

\begin{tabular}{clcc}
\hline \multicolumn{1}{c}{ Parameters } & \multicolumn{1}{c}{ Limit value } & Total $(\mathrm{n})$ & $\%$ \\
\hline \multirow{2}{*}{ HbA1c } & HbA1c $<6.5 \%$ & 45 & 78.9 \\
& HbA1c $\geq 6.5 \%$ & 12 & 21.1 \\
\hline \multirow{3}{*}{ hsCRP } & $\mathrm{hsCRP}<1 \mathrm{mg} / \mathrm{dL}$ & 14 & 24.6 \\
& $1 \leq \mathrm{hsCRP}<3 \mathrm{mg} / \mathrm{dL}$ & 26 & 45.6 \\
& $3 \leq \mathrm{hsCRP}<10 \mathrm{mgl} / \mathrm{dL}$ & 17 & 29.8 \\
\hline
\end{tabular}

*These data were normally distributed according to KolmogorovSmirnov test in whole data and each category. 
HbA1c $<6.5 \%$ group was $5.73 \%$, and the average of $\mathrm{HbA} 1 \mathrm{c}$ $\geq 6.5 \%$ group was $7.51 \%$. General characteristics of the subject are shown in Table 2 and Table 3.

\section{Differences between $\mathrm{HbA1c}<6.5 \%$ and $\geq 6.5 \%$ groups}

Independent Sample T-test was used to see the differences between various parameters within $\mathrm{HbAlc}<6.5 \%$ dan $\mathrm{HbA} 1 \mathrm{c} \geq 6.5 \%$ groups. It was found that hsCRP values were significantly different, while the value of sRAGE in both groups was not significantly different (Table 4).

\section{Correlation between hsCRP and sRAGE}

There was an inverse relationship between hsCRP and sRAGE levels for both in HbA1c $<6.5 \%(r=-0.073)$ and HbAlc $\geq 6.5 \% \quad(r=-0.022)$ groups. It is assumed that the increase of blood glucose levels, which represented by the examination of blood glucose levels for 3 months (HbA1c), causes enhancement of hsCRP accompanied by depletion of sRAGE.

\section{Correlation between hsCRP and sRAGE within $H b A 1 c<6.5 \%$ and $H b A 1 c \geq 6.5 \%$ group}

sRAGE have weak correlation to three categories of hsCRP based on the average of sRAGE on hsCRP groups in nondiabetic patients $(\mathrm{HbA} 1 \mathrm{c}<6.5 \%)$. hsCRP $<1 \mathrm{mg} / \mathrm{dL}$ and $3 \mathrm{mg} / \mathrm{dL} \leq \mathrm{hsCRP}<10 \mathrm{mg} / \mathrm{dL}$ groups had low negative correlation to sRAGE, only $1 \mathrm{mg} / \mathrm{dL} \leq \mathrm{hsCRP}<3 \mathrm{mg} / \mathrm{dL}$ group showed positive correlation (Table 5). In HbA1c $\geq 6.5 \%$ group, sRAGE showed strong positive correlation with $1 \mathrm{mg} / \mathrm{dL} \leq \mathrm{hsCRP}<3 \mathrm{mg} / \mathrm{dL}$ group $(\mathrm{r}>0.5)$, but showed low negative correlation in $3 \mathrm{mg} / \mathrm{dL} \leq \mathrm{hsCRP}<10 \mathrm{mg} / \mathrm{dL}$ group (Table 6).

\section{Discussion}

HsCRP is an important inflammatory marker and predictor of cardiovascular disease. ${ }^{9-11}$ hsCRP is synthesized mainly in hepatocytes as a response to inflammatory cytokines. The interaction between AGE and RAGE triggers escalation of inflammatory cytokine expressions, such as TNF- $\alpha$, IL-

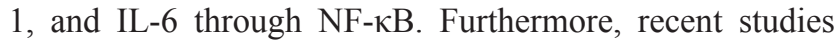
have shown that sRAGE modulate the synthesis of hsCRP. Circulating sRAGE has a negative correlation with hsCRP in patients with type 2 diabetes mellitus. ${ }^{12}$ Similar to this study, in both $\mathrm{HbA} 1 \mathrm{c}<6.5 \%$ and $\geq 6.5 \%$ groups of current study, there was a negative correlation between sRAGE and hsCRP. Previous studies have documented inverse correlations between sRAGE with $\mathrm{CRP}^{13}$ and low levels of sRAGE among persons with coronary heart disease ${ }^{14}$.

sRAGE can serve as a 'bait' receptor to catch ligand and able to inhibit the cellular signaling. AGE is estimated to be a linking factor between RAGE and metabolic syndrome or atherosclerosis. ${ }^{5}$ Other study confirmed these allegations by proposing new considerations that sRAGE potentially to

Table 2. General characteristics of subject in HbA1c $<6.5 \%$ group.

\begin{tabular}{lcccccc}
\hline & $(\mathrm{n})$ & Mean & Median & SD & Min & Max \\
\hline HbA1c $(\%)$ & 45 & 5.73 & 5.7 & 0.02 & 4.6 & 6.4 \\
hsCRP $(\mathrm{mg} / \mathrm{dL})$ & 45 & 2.23 & 1.78 & 0.23 & 0.3 & 7.8 \\
sRAGE $(\mathrm{pg} / \mathrm{mL})$ & 45 & 834.96 & 761.6 & 36.68 & 337.4 & 1,468 \\
\hline
\end{tabular}

Table 3. General characteristics of the subject in $\mathrm{HbA1c} \geq 6.5 \%$ group.

\begin{tabular}{lcccccc}
\hline & $(\mathrm{n})$ & Mean & Median & SD & Min & Max \\
\hline HbA1c (\%) & 12 & 7.51 & 6.95 & 0.28 & 6.5 & 11.1 \\
$\operatorname{hsCRP~(mg/dL)~}$ & 12 & 2.46 & 2.09 & 0.18 & 0.69 & 7.19 \\
sRAGE (pg/mL) & 12 & $1,094.38$ & 858.25 & 118.06 & 406.8 & 3,690 \\
\hline
\end{tabular}

Table 4. The differences between $\mathrm{HbA1}<<6.5 \%$ dan $\mathrm{HbA1c} \geq 6.5 \%$ group.

\begin{tabular}{lccc}
\hline & HbAlc $<6.5 \%$ & HbAlc $\geq 6.5 \%$ & $p$ value \\
\hline hsCRP $(\mathrm{mg} / \mathrm{dL})$ & 2.23 & 2.46 & $0.000^{*}$ \\
sRAGE $(\mathrm{pg} / \mathrm{mL})$ & 834.96 & $1,094.38$ & 0.09 \\
\hline
\end{tabular}

$* p<0.05$ : significant result 
Table 5. Average of sRAGE on hsCRP group in HbA1c $<6.5 \%$ population.

\begin{tabular}{lcccc}
\hline \multicolumn{1}{c}{ Category } & $\mathrm{n}$ & $\begin{array}{c}\text { Average of sRAGE } \\
(\mathrm{pg} / \mathrm{dL})\end{array}$ & $\begin{array}{c}\text { Average of hsCRP } \\
(\mathrm{mg} / \mathrm{dL})\end{array}$ & r value \\
\hline $\mathrm{hsCRP}<1(\mathrm{mg} / \mathrm{dL})$ & 13 & 930.25 & 0.573 & -0.078 \\
$1 \leq \mathrm{hsCRP}<3(\mathrm{mg} / \mathrm{dL})$ & 18 & 770.38 & 1.965 & 0.351 \\
$3 \leq \mathrm{hsCRP}<10(\mathrm{mg} / \mathrm{dL})$ & 14 & 725.2 & 3.01 & -0.13 \\
\hline
\end{tabular}

Table 6. Average of sRAGE on hsCRP group in HbA1c $\geq 6.5 \%$ population.

\begin{tabular}{lcccc}
\hline \multicolumn{1}{c}{ Category } & $\mathrm{n}$ & $\begin{array}{c}\text { Average of sRAGE } \\
(\mathrm{pg} / \mathrm{dL})\end{array}$ & $\begin{array}{c}\text { Average of hsCRP } \\
(\mathrm{mg} / \mathrm{dL})\end{array}$ & r value \\
\hline $\mathrm{hsCRP}<1(\mathrm{mg} / \mathrm{dL})$ & 1 & 934 & 0.69 & $\sim$ \\
$1 \leq \mathrm{hsCRP}<3(\mathrm{mg} / \mathrm{dL})$ & 8 & $1,222.26$ & 1.87 & 0.564 \\
$3 \leq \mathrm{hsCRP}<10(\mathrm{mg} / \mathrm{dL})$ & 3 & 806.8 & 4.61 & -0.387 \\
\hline
\end{tabular}

be used as complement parameter for hsCRP. sRAGE might be considered "the next CRP," due to its role in the setting of autoimmunity and inflammatory disease. ${ }^{7}$ Since sRAGE is a proteolytically cleaved form of RAGE that acts as an inhibitor of AGE-mediated signaling, it has been suggested that it could reduce the proinflammatory, prothrombotic and proatherosclerotic events of the activation of AGE-RAGE signalling. ${ }^{15}$ In line with this hypothesis, recent animal studies have shown that administration of sRAGE has a protective effect on diabetic vascular inflammation and atherosclerosis. ${ }^{16}$

On the increase of inflammatory conditions, such as diabetes or aging, sRAGE serum can be an inflammatory marker rather as bait. This is because of the evidence that sRAGE serum formation through proteolysis cutting is a part of the regulatory process and reflects the inflammation. In other hand, sRAGE concentration is associated with low prevalence of the metabolic syndrome, even with high level of hsCRP. These results indicated that the concentration of sRAGE may be a marker of inflammation in conditions of increased hsCRP and has a negative correlation with cardiovascular disease and its risk factors, such as metabolic syndrome.

In the early stages of diabetes without complications (HbAlc $<6.5 \%$ group) with low-grade of inflammation (hsCRP $<1 \mathrm{mg} / \mathrm{dL}$ ), the protective function was demonstrated with greater sRAGE levels. In this case, sRAGE acted as a decoy of RAGE. In the phase of further tissue damage (in the group with $\mathrm{HbA1c} \geq 6.5 \%$ ), the level of sRAGE was found to be low with an average hsCRP level of $4.61 \mathrm{mg} / \mathrm{dL}$, negative correlation with $\mathrm{r}=-0.387$, which is assumed to be related to the occurrence of complications through inflammatory pathways. Probably in early diabetes, without complications, levels of sRAGEs are higher than controls without diabetes. Perhaps shedding of the increased expression of cell surface RAGE is a protective mechanism to decoy and trap the accumulating deleterious ligands, such as AGE, S100/calgranulins, high-mobility group box 1 (HMGB1) and membrane attack complex (mac)-1. However, in late stages of the disease when quite advanced tissue damage has occurred, lower levels of sRAGEs may be associated with complications. ${ }^{17}$

Apparently, sRAGE is not only a promising predictive biomarker, but also a potential therapeutic target for the treatment and prevention, which requires further investigation. The relationship between sRAGE with cardiovascular disease may be influenced by genetic background with some recognized genotype of RAGE. ${ }^{18}$ RAGE polymorphisms are expected to affect the levels of sRAGE independently. Another thing is the limitations of our study due to the lack of identification in the diverse circulating forms of sRAGE. Therefore, since the proportion of diverse isoforms of sRAGE could differ among individuals, the identification of the isoforms is necessary to be pursued, so that pathophysiology of sRAGE with different isoform distribution in diabetic and nondiabetic patients could be explored.

\section{Conclusion}

In the early stages of diabetes with low-grade of inflammation (hsCRP $<1 \mathrm{mg} / \mathrm{dL}$ ) and without complications ( $\mathrm{HbAlc}<6.5 \%$ ), the protective function was demonstrated with greater sRAGE levels. However, in further phase 
with high-grade of inflammation $(3 \leq \mathrm{hsCRP}<10 \mathrm{mg} / \mathrm{dL})$ and presumably tissue damage ( $\mathrm{HbA} 1 \mathrm{c} \geq 6.5 \%$ ), the level of sRAGE was found to be low, which is assumed to be associated with complications. Hence, sRAGE could be suggested as a complementary marker for hsCRP to evaluate diabetic men with central obesity.

\section{References}

1. Rachmi CN, Li M, Alison Baur L. Overweight and Obesity in Indonesia: Prevalence and Risk Factors - A Literature Review. Public Health. 2017; 147: 20-9.

2. Hotamisligil GS. Inflammation and Metabolic Disorders. Nature. 2006; 444(7121): 860-7.

3. Dandona. Inflammation: The Link between Insulin Resistance, Obesity and Diabetes. Trends Immunol. 2004; 25(1): 4-7.

4. Daulay DY, As'ad S, Mappahya AA, Wijaya A. Concentration of Endogenous Secretory Receptor for Advanced Glycation End Products and Matrix Gla Protein in Controlled and Uncontrolled Type 2 Diabetes Mellitus Patients. Indones Biomed J. 2013; 5(1): 31-6.

5. Koyama H, Shoji T, Hisayo K. Plasma Level of Endogenous Secretory RAGE is Associated with Components of the Metabolic Syndrome and Atherosclerosis. Arterioscler Thromb Vasc Biol. 2005; 25(12): 2587-98

6. Yamamoto Y, Yamamoto H. RAGE-mediated Inflammation, Type 2 Diabetes, and Diabetic Vascular Complication. Front Endocrinol (Lausanne). 2013; 4: 105. doi: 10.3389/fendo.2013.00105. eCollection 2013.

7. Hudson BI, Harja E, Moser B, Schmidt AM. Soluble Levels of Receptor for Advanced Glycation Endproducts (sRAGE) and Coronary Artery Disease: The Next C-Reactive Protein? Arterioscler Thromb Vasc Biol. 2005; 25(5): 879-82.

8. Emanuele E, D'Angelo S, Tomaino C, Binetti G, Ghidoni R, Politi P, et al. Circulating Levels of Advanced Glycation End Products in Alzheimer Disease and Vascular Dementia. Arch Neurol. 2005; 62(11): 1734-6.
9. Todingrante A, Arief M, Bahrun U, Sandra F. Study of Low-grade Chronic Inflammatory Markers in Men with Central Obesity: Cathepsin S was Correlated with Waist Circumference. Indones Biomed J. 2013; 5(2): 115-20.

10. Ritawaty, Sukmawati IR, Patellongi I, Sandra F. Pathomechanism of Insulin Resistance in Men with Central Obesity: Correlation of GGT, GPx, hs-CRP and Plasma Total Cysteine. Indones Biomed J. 2013; 5(2): 101-6.

11. Sargowo D, Sandra F. Combination of Fibrinogen and High-sensitivity C-reactive Protein Measurements is Potential in Identification of Acute Coronary Syndrome. Indones Biomed J. 2015; 7(1): 31-6.

12. An XF, Zhao Y, Yu JY, Liu JS, Gu WJ, Gao F. Plasma sRAGE is Independently Associated with High Sensitivity C-reacive Protein in Type 2 Diabetes without Coronary Artery Disease. Diabetes Res Clin Pract. 2010; 87(3): e19-22.

13. McNair ED, Wells CR, Mabood Qureshi A, Basran R, Pearce C, Orvold J, et al. Modulation of High Sensitivity C-reactive Protein by Soluble Receptor for Advanced Glycation End Products. Mol Cell Biochem. 2010; 341: 135-8.

14. Basta G, Del Turco S, Navarra T, Mazzarisi A, Cocci F, Coceani M, et al. Inverse Association between Circulating Levels of Soluble Receptor for Advanced Glycation End-Products and Coronary Plaque Burden. J Atheroscler Thromb. 2012; 19: 941-8.

15. Vazzana N, Santilli F, Cuccurullo C, Davi G. Soluble Forms of RAGE in Internal Medicine. Intern Emerg Med. 2009; 4(5): 389401.

16. Bucciarelli LG, Wendt T, Qu W, Lu Y, Lalla E, Rong LL, et al. RAGE Blockade Stabilizes Established Atherosclerosis in Diabetic Apolipoprotein E-null Mice. Circulation. 2002; 106(22): 282735 .

17. Ramasamy R, Yan SF, Schmidt AM. The Diverse Ligand Repertoire of the Receptor for Advanced Glycation Endproducts \& Pathways to the Complications of Diabetes. Vascul Pharmacol. 2012; 57(5-6): 160-7.

18. Schalkwijk CG, Stehouwer CD. Stehouwer. Comment on: Selvin, et al. sRAGE and Risk of Diabetes, Cardiovascular Disease, and Death. Diabetes 2013;62:2116-2121. Diabetes. 2013 Oct;62(10):e25. doi: 10.2337/db13-1031. 